Research Article

\title{
Prevalence of TMJ Disorders among the Patients Attending the Dental Clinic of Ajman University of Science and Technology-Fujairah Campus, UAE
}

\author{
Kashef K. AlShaban $\mathbb{D}^{\mathbf{1}}$ and Zainab Gul Abdul Waheed ${ }^{2}$ \\ ${ }^{1}$ Faculty of Medical and Health Sciences, Emirates College of Technology, Abu Dhabi, UAE \\ ${ }^{2}$ Mint Dental Care LLC., Dubai, UAE \\ Correspondence should be addressed to Kashef K. AlShaban; kashefjo@yahoo.co.uk \\ Received 11 November 2017; Revised 22 March 2018; Accepted 8 April 2018; Published 10 May 2018 \\ Academic Editor: Li Wu Zheng
}

Copyright $\odot 2018$ Kashef K. AlShaban and Zainab Gul Abdul Waheed. This is an open access article distributed under the Creative Commons Attribution License, which permits unrestricted use, distribution, and reproduction in any medium, provided the original work is properly cited.

\begin{abstract}
The objective of this study was to determine the prevalence of temporomandibular joint (TMJ) disorders (if any) among the patients attending the dental clinic (for routine dental treatment) of Ajman University of Science and Technology (AUST)Fujairah campus, UAE, and its possible causes. A sample of 100 adult patients attending the dental clinic of AUST for different types of dental treatment were collected; the routine examination of the TMJ and possible disorders such as clicking, crepitation, limitation or deviation during mouth opening, or tenderness reveals that $41 \%$ of the sample experience varying degrees of disorders in the TMJ. Radiographs were taken if needed (panoramic radiograph). The information was collected and recorded for each patient through questionnaires.
\end{abstract}

\section{Introduction}

The proper function of (TMJ) depends upon the harmony of the different structures of the TMJ (including mandibular condyles, meniscus, glenoid fossa, ligaments, and muscles) that is well documented [1-4].

The TMJ continues in its function as usual until it is disturbed by external influences that affect the function of the joint, such as mechanical, psychological, occupational, and habits $[5,6]$.

The human body continues to try to repair its aggression; but if this continues, the body loses the ability to repair its aggression and the signs \& symptoms begin to appear.

The signs and symptoms of TMD involve orofacial and preauricular pain, as well as limitation of mouth opening, TMJ bruit during function and displacement of articular disc [7].

Disorders of the (TMJ), and how people respond to them, vary widely and fall into three main categories:

(1) Myofascial pain dysfunction syndrome involves tenderness or pain in the muscles that control jaw function.
(2) Internal derangement of the TMJ involves anterior displacement of the meniscus with or without auto reduction, dislocated jaw, or injury to the condyle.

(3) Arthritis refers to a group of degenerative/inflammatory joint disorders [8].

\section{Materials and Methods}

A random sample of 100 patients that attended the dental clinic for dental treatment underwent the routine examination of the TMJ, such as clicking, crepitation, limitation or deviation during mouth opening, and pain. $41 \%$ of these patients had varying degrees of TMD and were not aware of these disorders.

In the preliminary examination of the TMJ, we relied on the principles based on International RDC/TMD and the amendments thereto (version: 20 Jan 2014) [9].

This was done by individually examining each patient, taking a thorough history, and filling out a questionnaire for each patient, respectively. 


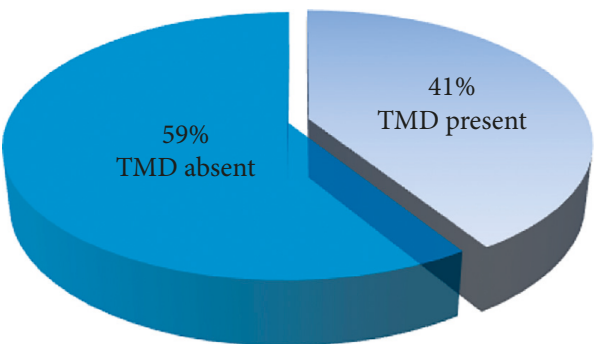

FIgURE 1: Pie chart demonstrating the presence and absence of TMD among the collected sample.

Physical examination of the collected sample was done in two ways:

(1) Lateral position: assessment of mandibular condylar movement by direct palpation over the joint while the patient opens and closes the mandible, at the preauricular area;

(2) Posterior position: assessment of mandibular condylar movement by direct palpation of the mandibular condyle while the patient opens and closes the mandible, through the external auditory meatus.

A mandibular opening less than $35 \mathrm{~mm}$ (the distance between the edges of upper and lower incisors) is considered in our study as restriction of mouth opening.

A thorough history was collected from the samples on any history of previous trauma to the head and neck region, any previous long dental appointments that could be the reason for any of the TMJ disorders, or any habits or any occupation-related habits that could precipitate a TMD.

Along with the clinical examination of the patient, the aid of radiographs (if necessary) was also taken.

\section{Results}

Among the randomly collected sample of a 100 patients, $41 \%$ (Figure 1) of the patient showed to have TMJ disorders out of which $65 \%$ were male patients and $35 \%$ were female patients (Figure 2).

Maximum percentage of patients (58\%) was between the age ranges of $19-29$ and the minimum (1\%) were between the age ranges of 60-69 (Figure 3).

Patients were further categorized based on their occupation for evaluation of any occupation-related habits affecting the TMJ (Figure 4). The maximum numbers of patients were firm employees $(30 \%)$, whereas the minimum numbers of patients were tailors and teachers (2\%) among the total sample of 100 patients.

Among the $41 \%$ of the patients having the TMJ disorder, only $5 \%$ (Figure 5 ) of the patients had an occupation-related habit that could be a precipitating factor of the TMJ disorders.

The $41 \%$ of subjects that had the TMJ disorder were examined of various TMJ pathologies such as clicking, crepitation, limitation, deviation, and tenderness.

As a result of the examination, most percentage of subjects presented to have clicking (89\%), and least percentage had crepitation (12\%) (Figure 6).

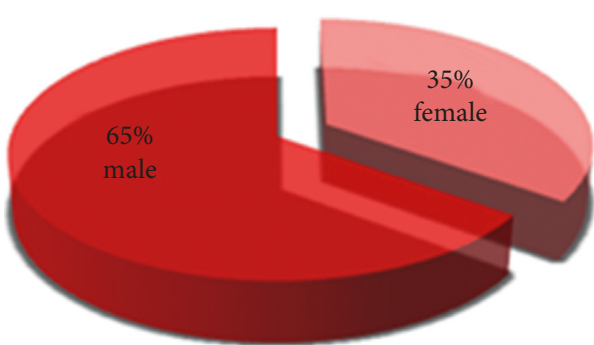

Figure 2: Pie chart demonstrating the percentages of male and female patients among the collected sample.

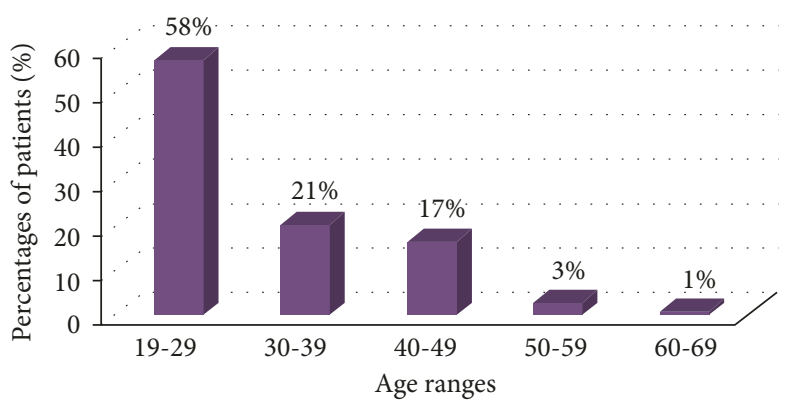

FIGURE 3: Bar graph showing the percentages of the collected sample of 100 patients and their respective age ranges.

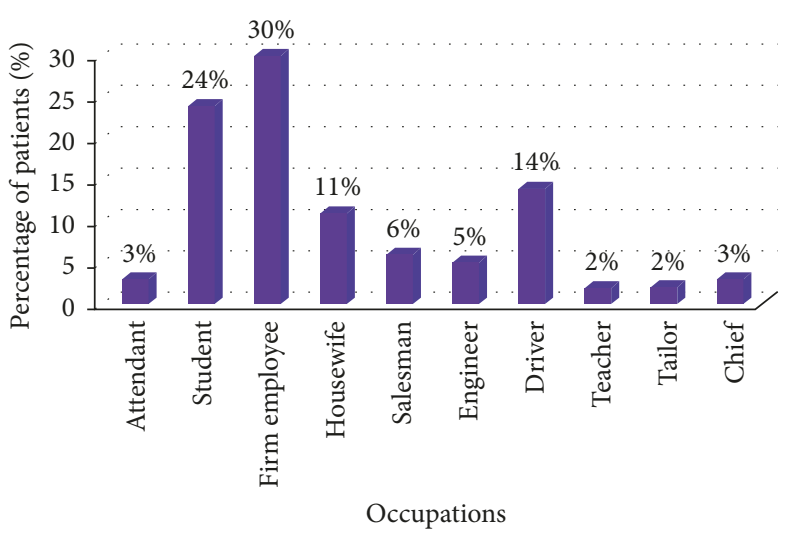

FIGURE 4: Bar graph representing the percentages of the collected sample of 100 patients with their respective occupations.

The involvement in TMJ Pathologies among the $41 \%$ of the patients either involved one side (unilateral) or both sides (bilateral) (Figures 7, 8, 9, 10, and 11).

The $41 \%$ of subjects were further inquired about five different criteria in order to achieve a conclusion of the possible causative factors of the TMJ disorders (Figure 12).

The subjects were inquired about the type of diet they consume and how it may affect the TMJ (Figure 13).

Figure 14 represents the percentages of patients and their respective habits.

\section{Discussion}

The research concluded that among the $41 \%$ of patients who had TMJ disorders, the most common TMJ pathology was clicking which was $89 \%$, and most patients had either bilateral 


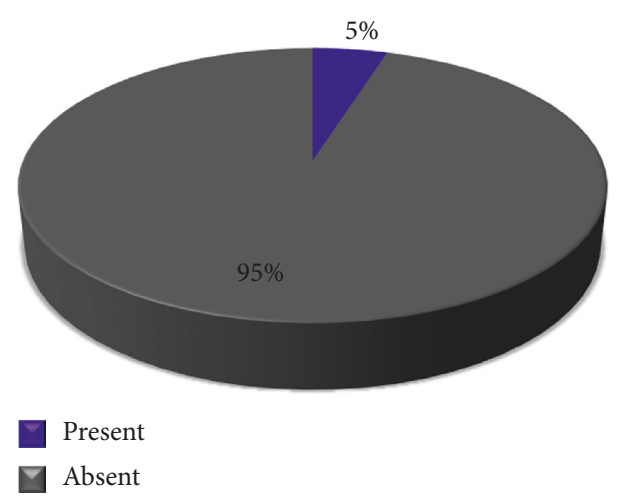

Figure 5: Pie chart representing the percentages of presence or absence of occupational habits in patients with TMJ disorders.

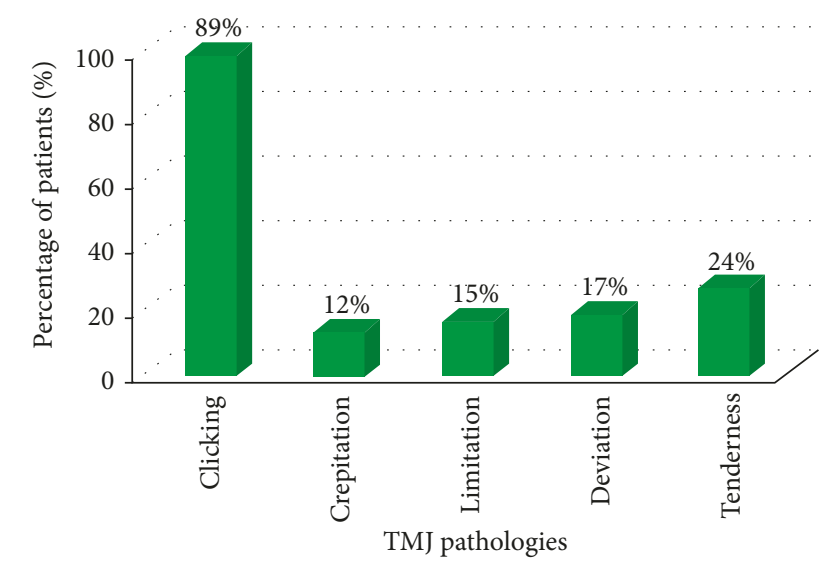

FIGURE 6: Bar graph showing the percentages of the patients having the different TMJ pathologies.

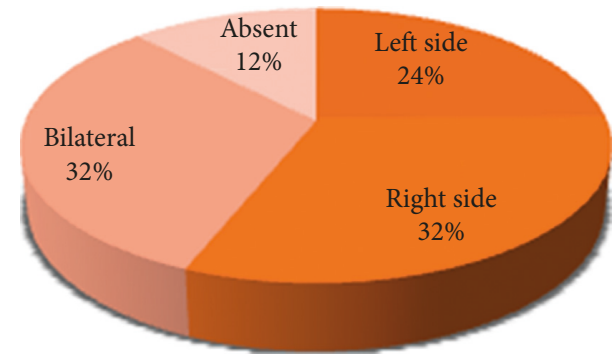

FIGURE 7: Pie chart demonstrating the percentages of patients with presence or absence of clicking on either side.

clicking (32\%) or clicking on the right side (32\%), followed by tenderness (24\%), deviation (17\%), limitation (15\%), and crepitation (12\%), as shown in related studies $[6,10,11]$.

Further, the patients were questioned on different criteria with the goal of identifying the causative factors of the disorder:

(i) The gravest cause concluded from the research was habits (32\%). Most patients had associated habits that resulted in TMJ disorders. Patients had habits like chewing gum (75\%), nail or lip biting (18\%), and bruxism (7\%). Most patients were not aware of the severity of the habits on the TMJ, as shown in related studies [12-17].

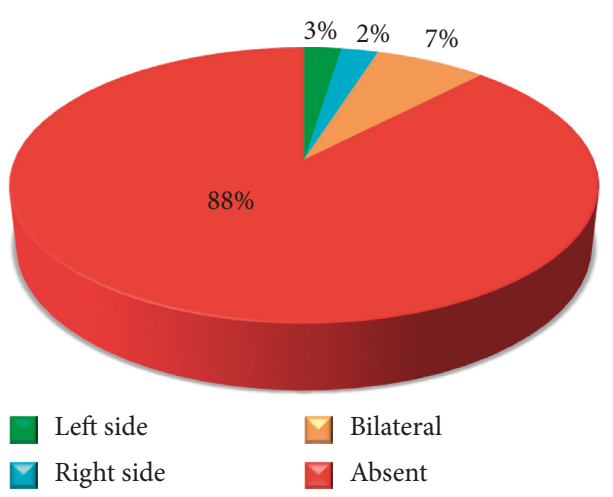

FIgURE 8: Pie chart demonstrating the percentages of patients with presence and absence of crepitation on either side.

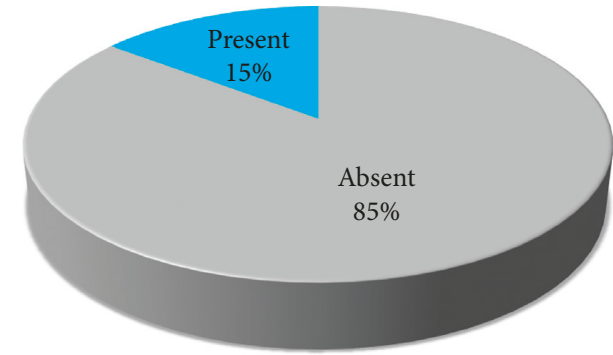

FIGURE 9: Pie chart representing the percentages of subjects with presence or absence of limitation during mouth opening.

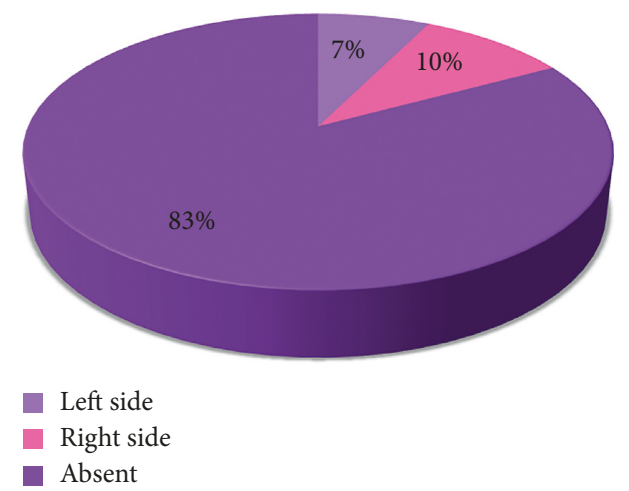

FIgURE 10: Pie chart demonstrating the percentages of patients representing presence or absence of deviation during mouth opening on either side.

(ii) The second most common cause concluded was previous dental treatments (29\%), specifying to a history of long dental appointments or previous orthodontic treatment [18].

(iii) Patients were inquired about having any history of trauma to the head and neck area that may have had an impact on the TMJ. The results concluded that $17 \%$ of the patient had a history of trauma, as shown in related studies $[19,20]$.

(iv) $10 \%$ of the patients had rheumatoid arthritis, as shown in related studies [21, 22].

(v) The lowest percentage was with occupational habits (5\%). They were noticed in two patients, one was 


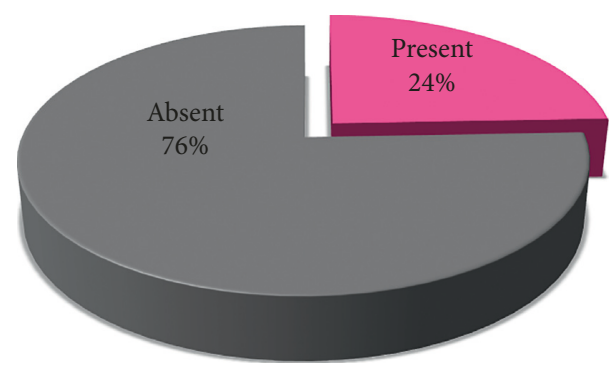

Figure 11: Pie chart representing the percentages of presence and absence of tenderness.

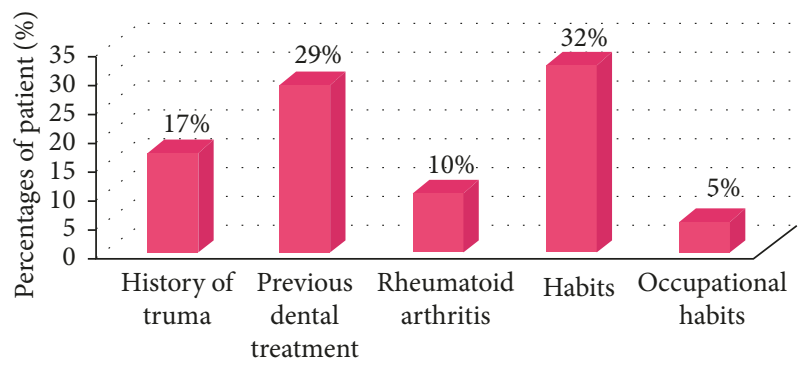

Figure 12: Bar graph representing the percentages of patients having different criteria.

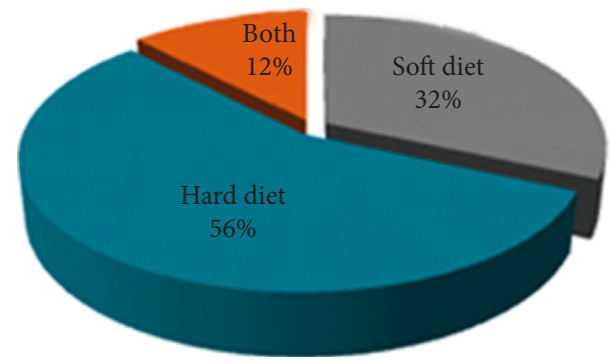

Figure 13: Pie charts demonstrating the percentages of patients whose diets are soft, hard, or both.

a teacher who had a history of clenching her jaws at the time of stress while teaching, and the other patient was a tailor having a history of biting off threads with his teeth.

(vi) Patients were also inquired on the type of diet they consumed to access any possible relationship between the type of diet and TMJ disorder:

The results stated that most patients had a hard diet (56\%) which could be a contributing factor in causing the disorders, as shown in related studies [23, 24]. Long-term consumption of hard diet has a direct impact on the TMJ; hence, the patients should be educated and motivated to discontinue the habit.

(i) In our study, the percentage of male patients who show TMJ disorders (65\%) was higher than that of female patients $(35 \%)$ :

Lee et al. [6] reported in their study, the predominance of the male with TMJ disorders; Another study [10] concluded that no significant relationship between females and males

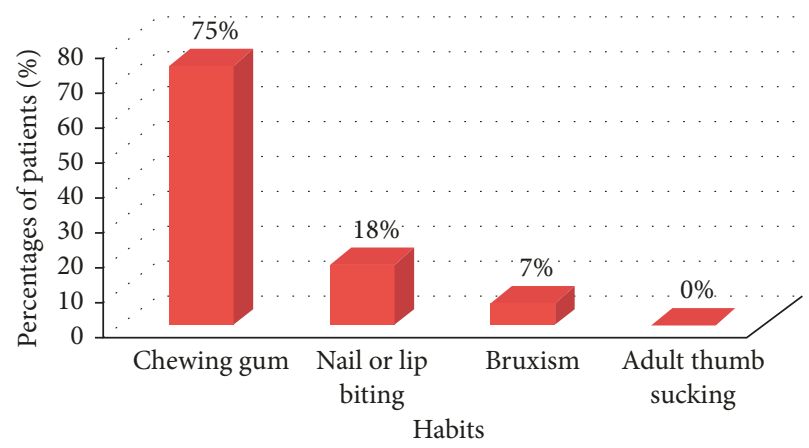

FIGURE 14: Bar graph representing the percentages of patients and their respective habits.

regarding TMJ disorders; Some studies [11, 12, 17, 25] have shown clearly the predominance of the female with TMJ disorders; Hirsch et al. [26] reported in their study, the predominance of the female with TMJ disorders during pubertal development, but the diagnosis remains unknown.

More research is needed to try to elucidate the relationship between female hormones and TMJ disorders (cause and effect).

(i) Finally, the psychological pressure (state-anxiety) and disorders play a role in TMJ disorders $[5,6,18,27]$ (it is not included in our study). Most probably, the psychological stress results in bruxism (bite force) that increases the load on the masticatory system which is manifested by TMJ dysfunction.

While conducting the research, it was observed that majority of the patients had lack of awareness of having a TMJ disorder and the adverse effects they could experience in the future. Therefore, patient education is an important factor in the treatment of the disorder, and grave importance should be given to this subject in order to reduce the incidence of the disorders.

Patients who had habits should be educated and enlightened about the severe effects they are on to the TMJ and the further possible severities to the TMJ if the habits are not discontinued.

4.1. Treatment. This analysis demonstrated that most of the patients from the collected sample needed a nonsurgical approach towards the treatment (95\%) such as splint therapy [28], physiotherapy [29], and transcutaneous electrical nerve stimulation [30]. The patients should be reassured and well informed regarding the at-home practices to relieve the symptoms.

Only $5 \%$ of the patient with long-term chronic conditions may need a surgical approach.

\section{Conclusions}

The research concluded that the incidence of TMJ Disorders is not uncommon among the patients attending the dental clinic of AUST-Fujairah campus.

TMD is a complex symptom, caused by multiple factors that are poorly understood. It affects people between 20 and 40 years old. 
About $20 \%$ to $40 \%$ of the adult population is affected to some degree.

The harmony and balance between the masticatory system and the function are crucial to keep the TMJ complex healthy. If anything that disrupts this equation, the body tries to correct it but to a certain limit; when the abnormal functions continue, at that time the signs and symptoms appear.

So, we can conclude (according to our research) that the main etiology of the TMD is the abnormal functions of TMJ due to incorrect habits and practices, as demonstrated by our study.

Hence, more importance should be given towards educating the patient on how to avoid behaviors that are abusive to the TMJ as patient education is also a key to successful TMJ rehabilitation.

\section{Data Availability}

Data supporting this research article are available from the corresponding author or first author on reasonable request.

\section{Conflicts of Interest}

The authors declare that there are no conflicts of interest regarding the publication of this paper.

\section{References}

[1] M. Bath-Balogh and M. Fehrenbach, Illustrated Dental Embryology, Histology, and Anatomy, Elsevier Saunders, St. Louis, MO, USA, 2011.

[2] M. Fehrenbach and S. Herring, Illustrated Anatomy of the Head and Neck, Elsevier, St. Louis, MO, USA, 2012.

[3] L. Moss-Salentijn, Biology of Mineralized Tissues: Prenatal Skull Development, Columbia University College of Dental Medicine Post-Graduate Dental Lecture Series, New York, NY, USA, 2007.

[4] M. L. Moss, "The non-existent hinge axis," American Institute of Oral Biology, pp. 59-66, 1972.

[5] G. D. Slade, R. Ohrbach, J. D. Greenspan et al., "Painful temporomandibular disorder: decade of discovery from OPPERA studies," Journal of Dental Research, vol. 95, no. 10, pp. 1084-1092, 2016.

[6] J.-Y. Lee, Y.-K. Kim, S.-G. Kim, and P.-Y. Yun, "Evaluation of Korean teenagers with temporomandibular joint disorders," Journal of the Korean Association of Oral and Maxillofacial Surgeons, vol. 39, no. 5, pp. 231-237, 2013.

[7] T. List and R. H. Jensen, "Temporomandibular disorders: old ideas and new concepts," Cephalalgia, vol. 37, no. 7, pp. 692-704, 2017.

[8] V. Tsai, Temporomandibular Joint Syndrome, February 2010.

[9] R. Ohrback, Ed., Diagnostic Criteria for Temporomandibular Disorders; Clinical Protocol and Assessment Instruments, International RDC/TMD Consortium Network, 2014, http:// www.rdc-tmdinternational.org.

[10] P. Modi, S. S. Shaikh, and A. Munde, "A cross sectional study of prevalence of temporomandibular disorders in university students," International Journal of Scientific and Research Publications, vol. 2, no. 9, 2012.

[11] M. Ebrahimi, H. Dashti, M. Mehrabkhani, M. Arghavani, and A. Daneshvar-Mozafari, "Temporomandibular disorders and related factors in a group of iranian adolescents: a cross-sectional survey," Journal of Dental Research, Dental Clinics, Dental Prospects, vol. 5, no. 4, pp. 123-127, 2011.

[12] G. Fernandes, A. L. Franco-Micheloni, J. T. T. Siqueira, D. A. G. Gonçalves, and C. M. Camparis, "Parafunctional habits are associated cumulatively to painful temporomandibular disorders in adolescents," Brazilian Oral Research, vol. 30, no. 1, 2016.

[13] L. Pereira, T. Pereira-Cenci, A. A. Del Bel Cury et al., "Risk indicators of temporomandibular disorder incidences in early adolescence," Pediatric Dentistry, vol. 32, no. 4, pp. 324-328, 2010.

[14] B. E. Cairns, "The influence of gender and sex steroids on craniofacial nociception," Headache, vol. 47, no. 2, pp. 319324, 2007.

[15] V. Motghare, J. Kumar, S. Kamate et al., “Association between harmful oral habits and sign and symptoms of temporomandibular joint disorders among adolescents," Journal of Clinical and Diagnostic Research, vol. 9, no. 8, pp. ZC45-ZC48, 2015.

[16] L. J. Motta, "Association between parafunctional habits and signs and symptoms of temporomandibular dysfunction among adolescents," Oral Health and Preventive Dentistry, vol. 11, no. 1, pp. 3-7, 2013.

[17] B. Murad, N. G. Sepah, B. Rehman, and T. Ahmad, "Parafunctional habits among undergraduate clinical students and house officers at Khyber College of Dentistry," Journal of Khyber College of Dentistry, vol. 6, no. 2, 2016.

[18] S. R. Habiba, M. Q. Al Rifaiy, K. H. Awan, A. Alsaif, A. Alshalan, and Y. Altokais, "Prevalence and severity of temporomandibular disorders among university students in Riyadh," The Saudi Dental Journal, vol. 27, no. 3, pp. 125-130, 2015.

[19] N. Pham Dang, E. Hugonnet-Boby, I. Barthelemy, and J. Shi, "Zygomatic arch fracture extended to the glenoid fossa: a cause of TMJ pain," Revue de Stomatologie, de Chirurgie Maxillo-faciale et de Chirurgie Orale, vol. 115, no. 2, pp. 121-123, 2014.

[20] G. L. Xiang, X. Long, M. H. Deng, Q. C. Han, Q. G. Meng, and B. $\mathrm{Li}$, "A retrospective study of temporomandibular joint ankylosis secondary to surgical treatment of mandibular condylar fractures," British Journal of Oral and Maxillofacial Surgery, vol. 52, no. 3, pp. 270-274, 2014.

[21] S. Witulski, T. J. Vogl, S. Rehart, and P. Ottl, "Evaluation of the TMJ by means of clinical TMD examination and MRI diagnostics in patients with rheumatoid arthritis," BioMed Research International, vol. 2014, Article ID 328560, 9 pages, 2014.

[22] L. M. Zwir, M. T. Terreri, S. A. Sousa, A. R. Fernandes, A. S Guimarães, and M. O. Hilário, "Are temporomandibular joint signs and symptoms associated with magnetic resonance imaging findings in juvenile idiopathic arthritis patients? A longitudinal study," Clinical Rheumatology, vol. 34, no. 12, pp. 2057-2063, 2015.

[23] E. M. Kogawa, P. S. Calderon, J. R. Lauris, C. R. Araujo, and P. C. Conti, "Evaluation of maximal bite force in temporomandibular disorders patients," Journal of Oral Rehabilitation, vol. 33, no. 8, pp. 559-565, 2006.

[24] B. I. Kim, S. H. Jeong, K. H. Chung, Y. K. Cho, H. K. Kwon, and C. H. Choi, "Subjective food intake ability in relation to maximal bite force among Korean adults," Journal of Oral Rehabilitation, vol. 36, no. 3, pp. 168-175, 2009.

[25] F. Bahrani, P. Ghadiri, and M. Vojdani, "Comparison of temporomandibular disorders in Iranian dental and nondental students," Journal of Dental Contemporary Practice, vol. 13, no. 2, pp. 173-177, 2012. 
[26] C. Hirsch, J. Hoffmann, and J. C. Türp, “Are temporomandibular disorder symptoms and diagnoses associated with pubertal development in adolescents? An epidemiological study," Journal of Orofacial Orthopedics/Fortschritte der Kieferorthopädie, vol. 73, no. 1, pp. 6-18, 2012.

[27] A. A. Pesqueira, P. R. Zuim, D. R. Monteiro, P. Ribeiro Pdo, and A. R. Garcia, "Relationship between psychological factors and symptoms of TMD in university undergraduate students," Acta Odontologica Latinoamericana (AOL), vol. 23, no. 3, pp. 182-187, 2010.

[28] N. N. Giannakopoulos, E. N. Katsikogianni, D. Hellmann et al., "Comparison of three different options for immediate treatment of painful temporomandibular disorders: a randomized, controlled pilot trial," Acta Odontologica Scandinavica, vol. 74, no. 6, pp. 480-486, 2016.

[29] J. M. Pho Duc, S. V. Hüning, and M. L. Grossi, "The effectiveness of physiotherapy in the management of temporomandibular disorders: a systematic review and meta-analysis," International Journal of Prosthodontics, vol. 29, no. 4, pp. 340-350, 2016.

[30] A. P. Ferreira, D. R. Costa, A. I. Oliveira et al., "Short-term transcutaneous electrical nerve stimulation reduces pain and improves the masticatory muscle activity in temporomandibular disorder patients: a randomized controlled trial," Journal of Applied Oral Science, vol. 25, no. 2, pp. 112-120, 2017. 


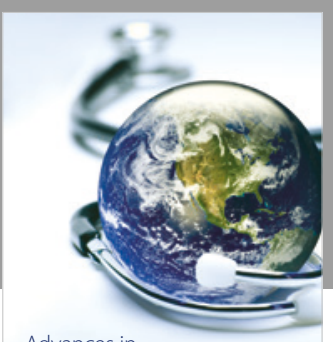

Advances in
Public Health

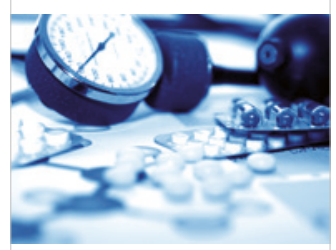

Case Reports in

Medicine

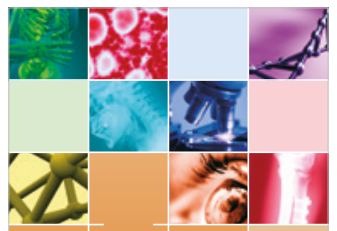

niernational Journal of

Biomaterials
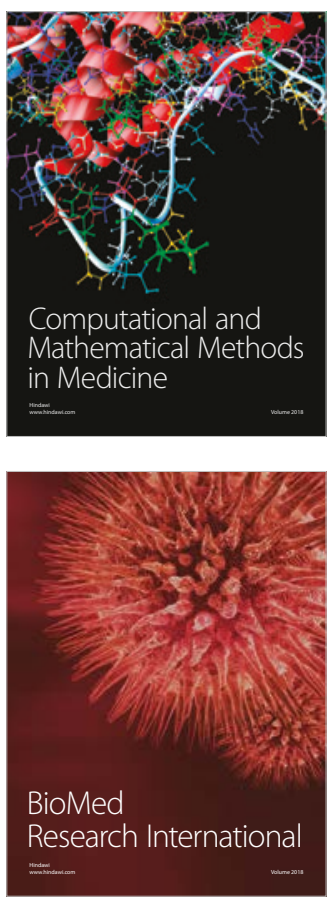

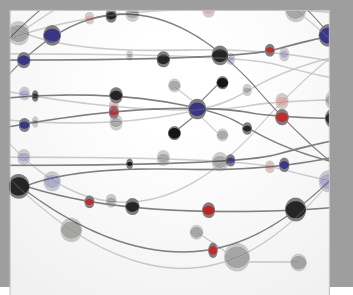

The Scientific World Journal Dentistry

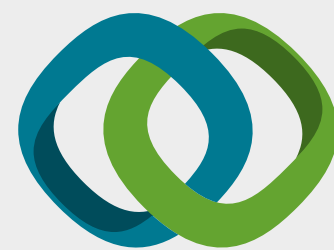

Hindawi

Submit your manuscripts at

www.hindawi.com
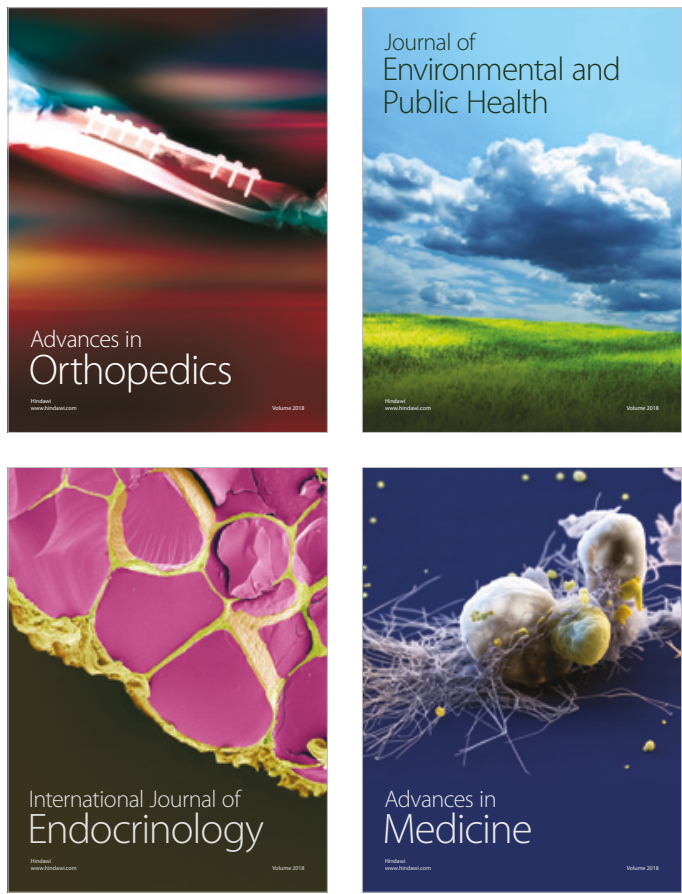
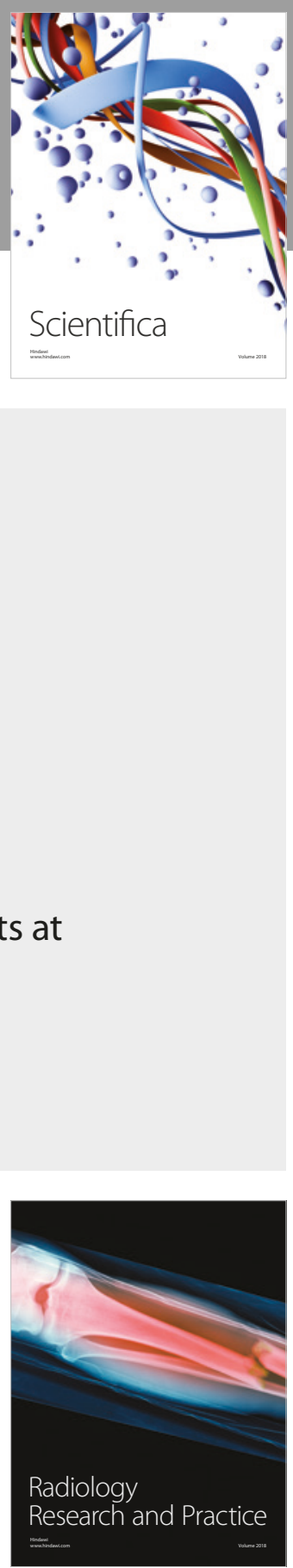

Scientifica

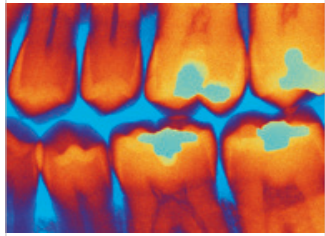

Case Reports in

Dentistry
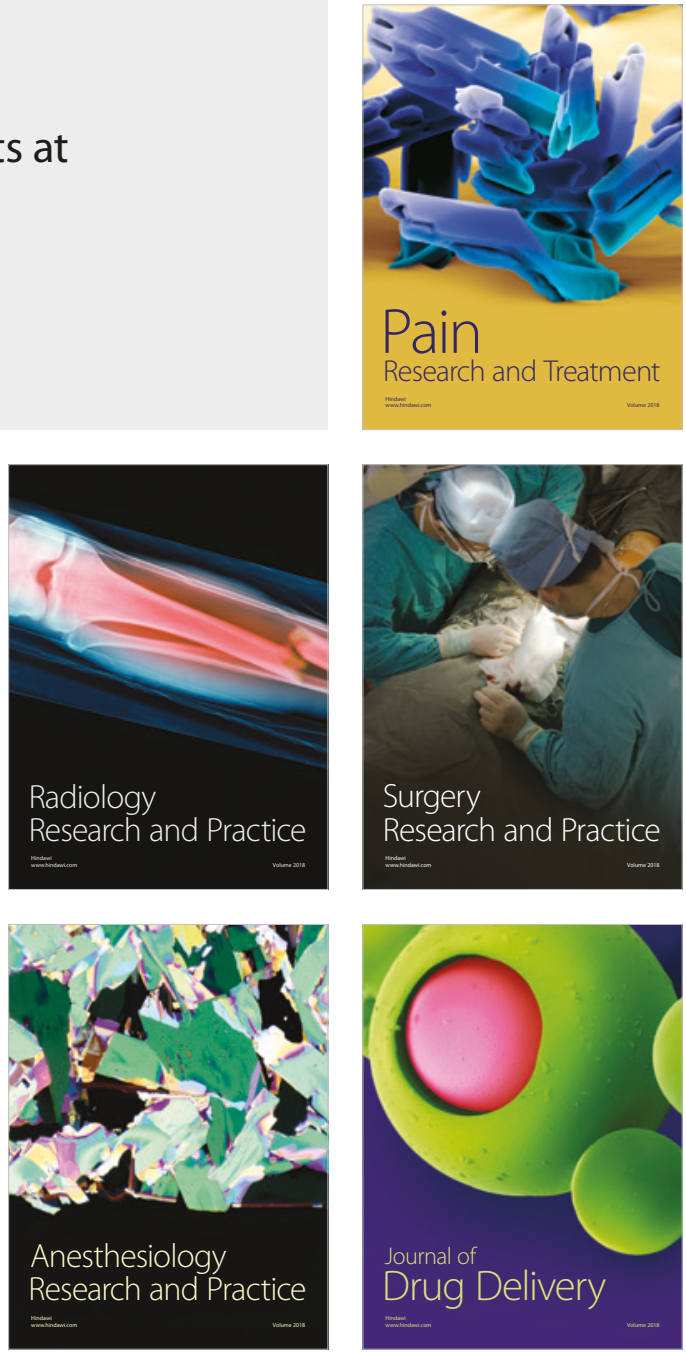